\title{
Wireless Sensor Network for Monitoring Maturity Stage of Fruit
}

\author{
Monai Krairiksh ${ }^{1}$, Jatuphong Varith ${ }^{2}$, Apichan Kanjanavapastit ${ }^{3}$ \\ ${ }^{1}$ Faculty of Engineering, King Mongkut's Institute of Technology Ladkrabang, Bangkok, Thailand \\ ${ }^{2}$ Department of Agricultural and Food Engineering, Faculty of Engineering and Agro-Industry, \\ Maejo University, Chiangmai, Thailand \\ ${ }^{3}$ Department of Telecommunication Engineering, Faculty of Engineering, \\ Mahanakorn University of Technology, Bangkok, Thailand \\ E-mail:kkmonai@kmitl.ac.th,jatupong@mju.ac.th, \\ apichan@mut.ac.th \\ Received August 2, 2011; revised August 26, 2011; accepted September 5, 2011
}

\begin{abstract}
In this letter, we present a wireless sensor network for monitoring the maturity stage of fruit. A dual-polarization coupled patch sensor, which is robust to environmental changes, was designed to operate at $2.45 \mathrm{GHz}$. It was attached to a Durian fruit for a period of days to measure the magnitude of mutual coupling corresponding mainly to the starch concentration of its pulp. Signal was transmitted from a sensor node, via tree nodes, to a master node that displays the variations occurring in the period. The maximum mutual coupling occurred at the maturity stage of $60 \%$ whereas the minimum occurred at $70 \%$. These results demonstrate that this wireless sensor network can enable fruit growers to harvest their Durians at an appropriate time, providing a reliable quality control for export.
\end{abstract}

Keywords: Fruit Sensor, Maturity Stage Monitoring, Wireless Sensor Network, Pre-harvest Control

\section{Introduction}

As climacteric fruits ripen, the starch in their pulp turns into sweet-tasting sugar. It is necessary to harvest them at an appropriate time, i.e., harvesting them too early and they will no longer ripen properly, harvesting them too late then they must be consumed within a few days before they are spoiled. Timing the harvest for sufficient shipping time for export is absolutely crucial. Durio zibethinus Murray (Durian) is a major export fruit that brings into Thailand large amount of income every year. The conventional method for monitoring the maturity stage of Durian is by counting the number of days after full-bloom. However, the results are often inaccurate due to variations in the environment, e.g., temperature and humidity [1]. Therefore, a number of research projects have been conducted to develop sensors for monitoring the maturity stage of Durian [2-4]. Yet, these are generally only used to monitor post-harvest products.

This work presents a wireless sensor network for monitoring the maturity stage of Durian in the pre-harvest monitoring scheme.

\section{Dual-Polarization Coupled Patch Sensor}

It has been shown in [5] that starch and reducing sugar in Durian pulp vary, respectively, proportionally and inversely proportionally to the days after full-bloom. The peel is relatively unchanged. These changes gradually decrease the dielectric constant of the pulp in the days following full-bloom [6,7].

Due to severe environment during Durian-growing season, which is highly humid with heavy rains, a dual-polarization coupled patch was selected to ensure that measurements were robust to environmental changes. For the sensor, using coupled patch antenna, we simulated a Durian fruit as a pulp covered by a prickle peel with CST microwave studio software [8]. The Durian was modeled as an ellipsoid, see Figure 1(a), with the major and minor axis of $30 \mathrm{~cm}$ and $20 \mathrm{~cm}$, respectively. This is the standard size for export Durian. The thickness of the prickle peel was $1 \mathrm{~cm}$. Figure 1(b) shows the diagram of the dual-polarization coupled patch sensor which was fabricated on an FR-4 substrate $1.6 \mathrm{~mm}$ high. The dielectric constant of the substrate was 4.4 . The right 


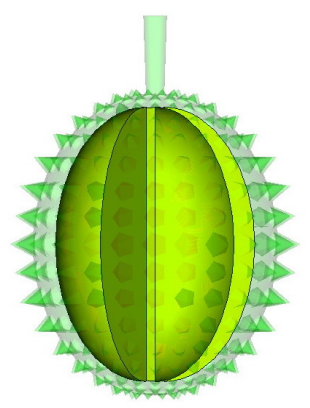

(a)

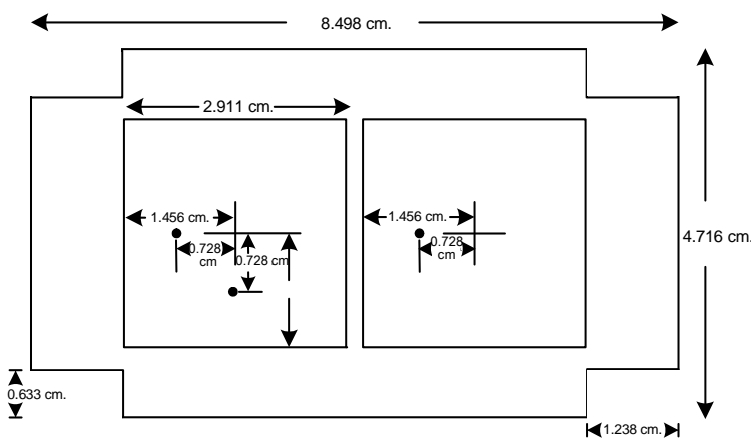

(b)

Figure 1. Durian model and coupled patch sensor (a) Durian model; (b) Dual-polarization coupled patch sensor.

patch was used for transmitting a microwave frequency of $2.45 \mathrm{GHz}$ whereas the left patch was used for receiving the coupled signal. The probe along the same line with the transmitting probe was used for receiving the parallel polarization signal whereas the one below it was used for receiving the perpendicular polarization signal.

The dielectric constant of the peel was kept constant at 15 whereas the dielectric constant of the pulp was varied from 62 to 22. The variations of the magnitude of mutual coupling for parallel polarization are shown in [9]. They are plotted together with those for perpendicular polarization as shown in Figure 2. It can be seen that the mutual coupling decreased as the dielectric constant decreased from 62 to 37, but then increased slightly afterwards. Thus, the variation in mutual coupling can be used as an indicator for monitoring the maturity stage of Durian. It should be noted that the perpendicular polarization showed higher mutual coupling due to the effect of near-field region of the antenna.

\section{Wireless Sensor Network}

The architecture of the wireless sensor network is shown in Figure 3. It shows sensor nodes attached to Durian fruits sensing the magnitude of the mutual coupling of the fruits and sending signal to a tree node installed on each tree. The signals were then sent from each tree via

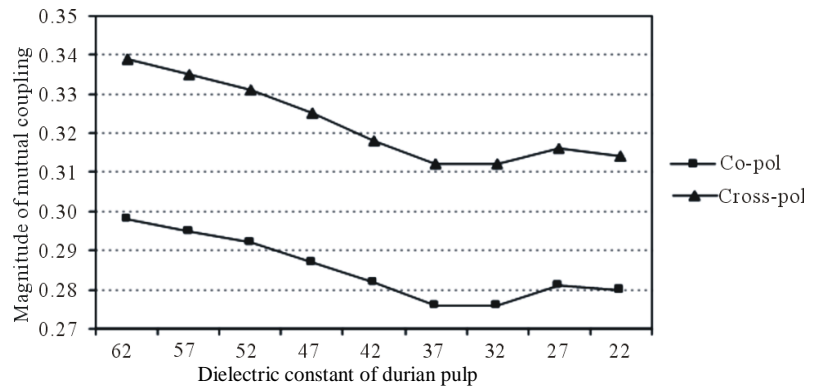

Figure 2. Simulation of parallel and perpendicular polarization mutual coupling when dielectric constant of pulp was varied (dielectric constant of peel was fixed at 15).
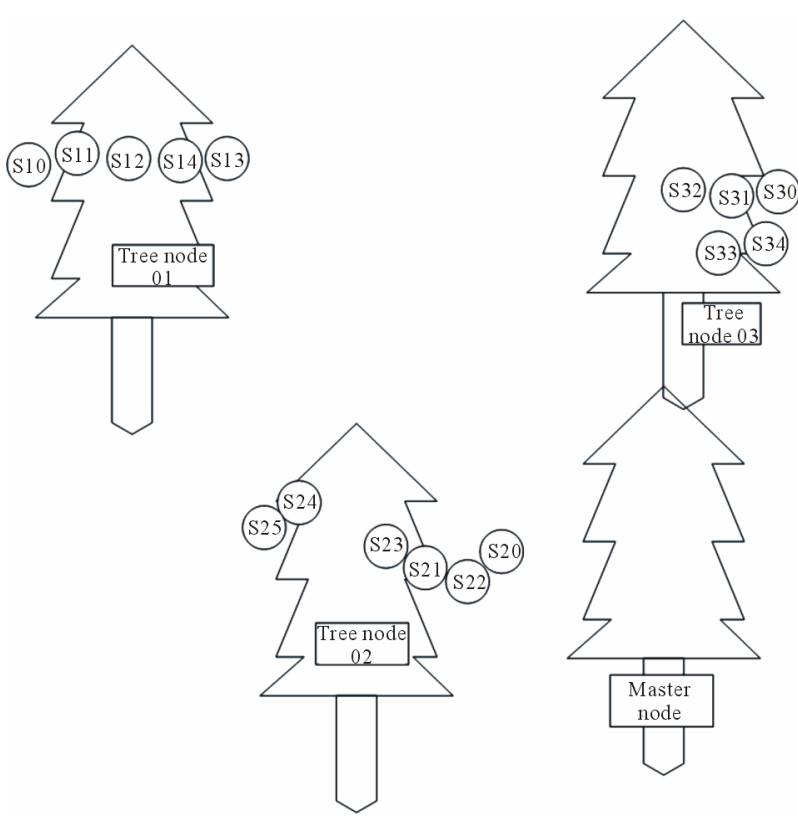

Figure 3. System architecture.

other tree nodes to a master node using a routing protocol similar to the directed diffusion method [10]. For a large tree, in order to overcome the path loss on the tree, it was possible to install several tree nodes on the tree. Each tree node oversaw a number of sensor nodes and communicated via other tree nodes to the master node. In order to keep the cost low, readily available wireless communication modules from local market were used for both sensing and communications. The operating frequency was $2.45 \mathrm{GHz}$. An experiment was set up to measure the path loss on a tree and a link budget was calculated for the system using a TRW2.45 communication module operating at $2.45 \mathrm{GHz}$. It had an output power of $+4 \mathrm{dBm}$ and a sensitivity of $-80 \mathrm{dBm}$. From the measurement, the path losses at various positions on the tree from the stem $1.5 \mathrm{~m}$ above ground were around 65 $\mathrm{dB}$. It was evident that a sufficient margin of $27 \mathrm{~dB}$ was obtained. 


\section{Experimental Results}

A dual-polarization coupled patch sensor was designed as detailed above. It was equipped with two RF switches as shown in Figure 4. The first RF switch (SW01) was connected with the transmitting patch and a monopole antenna for communications. The TRW2.45 was used for transmitting $2.45 \mathrm{GHz}$ to the sensor and the monopole whereas the second RF switch (SW02) was connected to a MAXIM MAX4004 power detector and the parallel and perpendicular polarization ports of the receiving patch. After converted to digital signal by a 12 bit ADC, the signal was input into an MCS-51 microcontroller which was used for controlling RF switches. Communications on a tree was tested on a 20-meter high Durian tree at Nakornsrithamarat, Thailand, in July 2009.

Eight sensors were utilized for measuring the mutual coupling of eight fruits of the same size. Measurements were conducted during 10 am to 12 pm every day since the humidity was low and the rain was not as heavy as that in the other periods of the day. The averaged results of coupling voltage of parallel and perpendicular polarization from the ADC throughout the data collecting period are plotted in Figure 5. It is apparent that on the $94^{\text {th }}$ day after full-bloom, the coupled voltage increased from $1.9 \mathrm{~V}$ and $2.2 \mathrm{~V}$ for the parallel polarization and perpendicular polarization, respectively. It reached the maximum on the $97^{\text {th }}$ day where the parallel polarization and perpendicular polarization were $2.15 \mathrm{~V}$ and $2.4 \mathrm{~V}$, respectively. The coupled signals then decreased gradually until the minimum was reached on the $100^{\text {th }}$ day. Then, it happened to increase again. Please note that, if only the parallel or perpendicular polarization was used, there might be an error since the coupled voltage for the parallel polarization was increasing while that for the perpendicular polarization was fluctuating, probably due to environmental changes. During the $94^{\text {th }}-97^{\text {th }}$ days, the variations in the parallel polarization were quite large compared to those in the perpendicular polarization. On

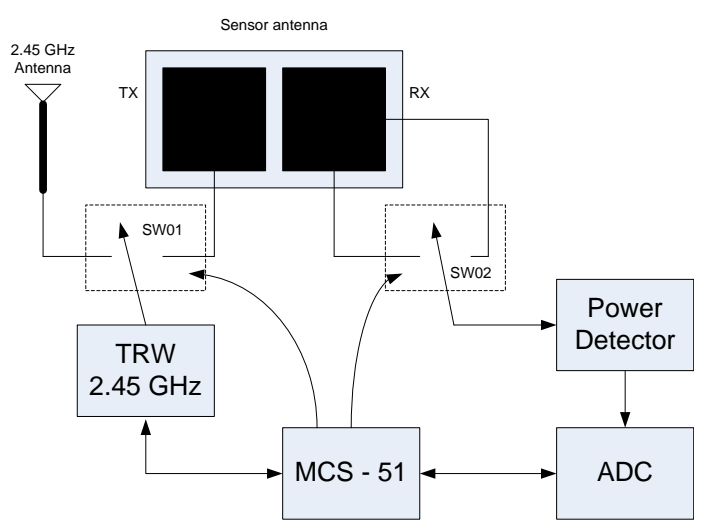

Figure 4. Diagram of a sensor and communication system.

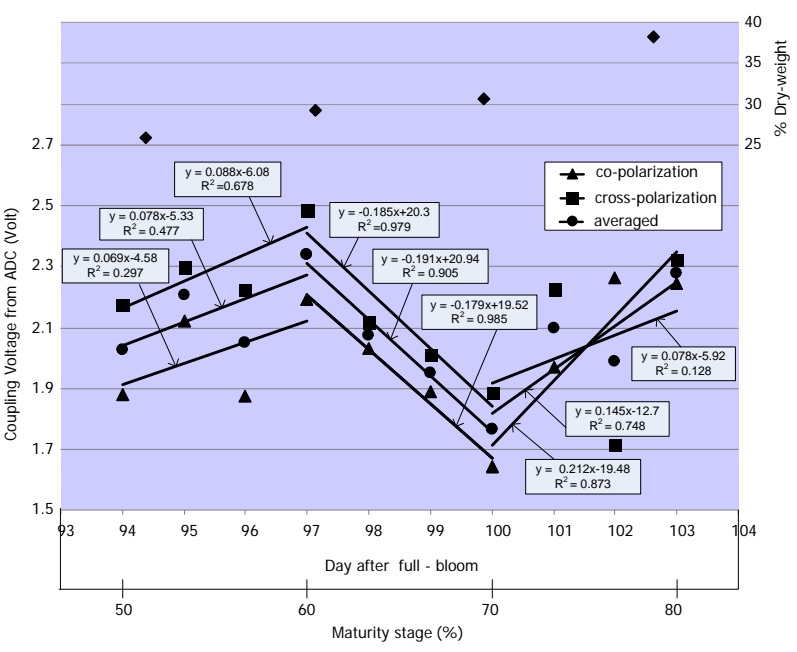

Figure 5. Measurement results.

the other hand, during the $100^{\text {th }}-104^{\text {th }}$ days, the parallel polarization was increasing whereas the perpendicular polarization was decreasing and then increasing slightly. When the results of the parallel and perpendicular polarizations were averaged, the measurement reliability increased. The averaged results of both polarizations provided more reliable results than that from each single polarization measurement. Together, the maximum and minimum coupled signals on the $97^{\text {th }}$ and $100^{\text {th }}$ days after full-bloom were a good indicator of the maturity stage of Durian.

During this data collecting period, three Durian fruits of the same age were sampled every three days to investigate their physical properties, i.e., starch concentration, reducing sugar concentration, color, etc. This information was used to evaluate the maturity stage of Durian by comparing it with the conventional method in [2]. The horizontal axis of Figure 5 shows the maturity stage corresponding to the days after full-bloom whereas the vertical axis shows the coupling voltage from the ADC and\% dry-weight of Durian pulp. Figure 5 shows that the $\%$ dry-weight of $29 \%$ and $32 \%$ corresponds to the days when the maximum and minimum coupling took place. It also shows that the maturity stage of $60 \%-70 \%$ was indicated by the \% dry-weight of $29 \%$ - 32\%. Hence, the transition of the coupling voltage from the ADC from the maximum to the minimum represents the maturity stage of $60 \%-70 \%$.

It is recommended that sensors be installed on the Durian fruits that are representatives of Durians of the same season around the $94^{\text {th }}$ day after full-bloom, which corresponds to $50 \%$ maturity stage. Coupling voltage should be measured every day. The maximum voltage indicates the maturity stage of $60 \%$. The results of this experiment show that the maturity stage increases from $60 \%$ to $70 \%$ within three days. It should be pointed out 
that a harvesting date can also be predicted by calculating the slope of the measured mutual coupling. And when the slope changes from negative to positive, it is time that Durians should be harvested.

According to the conventional method of counting the days after full-bloom, Durian is at the maturity stage of $75 \%$ around 120 days after full-bloom [1]. However, Figure 5 shows that, actually, on the $101^{\text {st }}$ day, the maturity stage was $75 \%$ already. Therefore, under some conditions, it is quite possible that fruit growers may harvest Durian at the wrong time. The proposed sensor may be a good alternative for pre-harvesting quality control of this fruit.

\section{Conclusions}

A dual polarization coupled patch antenna for sensing maturity stage of Durian was proposed. The averaged mutual coupling signal can indicate the appropriate time for harvesting Durians, which is absolutely essential for controlling its quality for export. This work demonstrates an application for Durian quality control. Future work will apply to other climacteric fruits.

\section{Acknowledgments}

This work was supported by the National Research Council of Thailand (NRCT) and the Thailand Research Fund (Grant No.RTA5180002). The authors appreciate P. Sooksumrarn, T. Limpiti, P. Yoiyod, P. Leekul and T.Tantisoparak for implementing the system and data collection.

\section{References}

[1] P. Lertrut, B. Rattanachinakorn, S. Vijitranont, S. Suthiarom, S. Pavenakarn, H. Hirunpradit, S. Juntarapunnik, and S. Sluckpetch and Durian, Ministry of Agriculture and Cooperative, No.13/2547, 2003.
[2] K. Kalayanamitra, "Evaluation and Classification of Durian Fruit Maturity and its Relationship with Chemical Constituents," Thai Journal of Agricultural Science, Vol. 38, No. 1-2, 2005, pp. 45-54.

[3] S. Ketsa and T. Dangkanit, "Firmness and Activities of Polygalacturonase, Pertinesterase, $\beta$-Galactosidase and Cellulose in Ripening Durian Harvested at Different Stages of Maturity,” Scientia Horticulture, Vol. 80, 1999, pp. 181-188.

[4] T. Rutpralom, K. Chamnongthai and P. Kumhom, "Nondestructive Durian Maturity Determination by Using Microwave Free Space Measurement," IEEE International Symposium on Circuits and Systems, Island of Kos, 21-24 May 2006, pp. 441-444.

[5] S. Suttapa, J. Varith, M. Krairiksh, C. Noochuay and J. Phimpimol, "Microwave Sensor Response in Relation to Durian Maturity," Proceedings of the 5th CIGR Section VI International Symposium on Food Processing and Monitoring Technology in Bioprocesses and Food Quality Management, Potsdam, 31 August-2 September 2009.

[6] T. Motwani, K. Seetharaman and R. C. Anantheswaran, "Dielectric Properties of Starch Slurries as Influenced by Starch Concentration and Gelatinization," Carbohydrate Polymers, Vol. 67, No. 1, 2007, pp. 73-79. doi:10.1016/j.carbpol.2006.04.017

[7] X. Liao, G. S. V. Raghavan, J. Dai and V. A. Yaylayan, "Dielectric Properties of $\alpha$-D-Glucose Aqueous Solutions at $2450 \mathrm{MHz}$," Food Research International, Vol. 36, No. 5, 2003, pp. 485-490. doi:10.1016/S0963-9969(02)00196-5

[8] CST Microwave Studio User’s Manual, 2006.

[9] M. Krairiksh, J. Varith, A. Kanjanavapastit, C. Phongcharoenpanich, A. Thanachayanont, P. Sirisuk and M. Chongcheawchamnan, "Microwave Sensor for Durian Inspection," Proceedings of 2009 IEEE International Conference on Antennas, Propagation and Systems, Johor, 3-5 December 2009, pp. 221-1-221-4.

[10] C. Intanagonwiwat, R. Govindan and D. Estrin, "Directed Diffusion: A Scalable and Robust Communication Paradigm for Sensor Networks," Proceedings of the 6th Annual International Conference on Mobile Computing and Networking, Boston, 6-11 August 2000, pp. 56-67. 